\title{
DECADÊNCIA CONTEMPORÂNEA: O ESFACELAMENTO DA EXPERIÊNCIA E DA NARRATIVA EM WALTER BENJAMIN
}

\author{
Andrey Rodrigues da Silva
}

\section{RESUMO}

O presente artigo pretende discorrer acerca do esfacelamento da experiência e o consequente desaparecimento da arte de narrar, junto ao caráter prático e a importância da narração, segundo Walter Benjamin. As experiências que outrora enriqueciam o viver, criando provérbios de grande valia, foram substituídas aos poucos pela barbárie, que ostenta toda a miséria e a pobreza de experiências na cultura do vidro, que uniformiza e é desprovida de aura.

Palavras-chave: Barbárie. Decadência. Experiências. Narrativa. Walter Benjamin.

\section{CONTEMPORANY DECLINE: THE DISMEMBERMENT OF EXPERIENCE AND NARRATIVE IN WALTER BENJAMIN}

\begin{abstract}
This article aims to discuss about the collapse of the experience and the disappearance of the art of narration, beyond the utilitarian and the importance of the story, according to Walter Benjamin. The experiences that once enriched the live, created proverbs that in times of need would be great value, were gradually replaced by a great barbarity, which boasts all the misery and experiences of poverty that now is ; the glass culture, which standardizes and is devoid of aura.
\end{abstract}

Keywords: Barbarism. Decadence. Experiences. Narrative. Walter Benjamin. 


\section{Introdução}

A experiência sempre foi uma forma de transmissão de conhecimento aos mais jovens, visando prepará-los para o que estaria por vir, livrando-os de situações embaraçosas ou perigosas, como um guia que traz segurança para evitar que o indivíduo fique à mercê da própria sorte. Não é à toa que desde cedo ouvimos conselhos, sofremos censuras de adultos por algumas atitudes, visando corrigir nossa postura moral. Além dos conselhos, as experiências nos são passadas através da narrativa, responsável por intercambiar as experiências. Mas a experiência sofre com a era de indefinição em que vivemos: o desenvolvimento da técnica industrial trouxe consigo uma faca de dois gumes: Se por um lado os avanços tecnológicos facilitaram a vida, por outro defasaram as relações humanas, provocando o esfacelamento das experiências, e acarretando "a extinção da arte de narrar" (BENJAMIN, 1985, 200). A narrativa fascina porque não é explicada. Isso a faz transcender sua época. $E$, ao deixar no ar múltiplas interpretações, ela colabora para o lado prático da existência: "o conselho, tecido na substância viva da existência tem um nome: sabedoria" (BENJAMIN, 1985, 200-201). Mas o que teria provocado a catástrofe do desaparecimennto da experiência? O surgimento de experiências negativas, trazidas pela guerra e pela sobreposição da técnica ao homem podem ser apontados como causas. $\mathrm{O}$ ancião, aquele que possuía a sabedoria, sendo por isso habilitado à arte de narrar, foi aos poucos perdendo a sua importância na sociedade, e cedendo seu espaço ao novo, à novidade, ao atual. A experiência dos antigos foi sendo asfixiada pela implantação de novas tecnologias, de um novo modus vivendi, que acabou transformando a cultura em barbárie. A aceleração da vida com o monstruoso desenvolvimento da técnica, apesar do surgimento de outros saberes, não consegue preencher o vazio que se estabeleceu com a extinção da experiência, acarretando a abreviação da arte de narrar. Uma das suas consequências é o aparecimento da informação.

\section{As razões para a baixa das experiências}


Walter Benjamin considera que a geração que viveu o período da primeira guerra mundial (1914-1918), sofreu uma das mais terríveis experiências da história. $O$ horror vivido na guerra de trincheiras, a inflação e a fome contribuíram para o aparecimento da barbárie cultural que viria posteriormente. A destruição das formas positivas da experiência levara à uma angustiante multiplicidade de ideias, visando preencher o vazio que surgira. Novas formas de terapia, ciências, religiões e condutas alimentícias se fizeram presente numa tentativa de renovação que acarretou uma galvanização.

A angustiante riqueza de ideias que se difundiu, entre, ou melhor, sobre as pessoas, coma renovação da astrologia e da ioga, da Christian Science e da quiromancia, do vegetarismo e da gnose, da escolástica e do espiritualismo, é o reverso dessa miséria. Porque não é uma renovação autêntica que está em jogo, e sim uma galvanização. (BENJAMIN, 1985, 115)

O novo conceito de barbárie que é introduzido é considerado aceito como desafio. O indivíduo é forçado a partir para frente, começar de novo e contentarse com pouco. Homens que tiveram a coragem de começar de novo, como Descartes, revolucionaram algumas áreas do conhecimento (BENJAMIN, 1985, 116). Outro exemplo é Einstein. Porém, não podemos esquecer o desafio que representam as novas condições ditadas pela tecnologia: Surge a cultura de vidro (BENJAMIN, 1985, 117), esse material frio e liso parece ajustar-se à natureza das novas consciências, inexorável aos apelos da tradição.

A cultura de vidro surge em um momento no qual o capitalismo está ganhando cada vez mais espaço e consequentemente provocando a sobreposição da técnica sobre o homem. É uma cultura tecnicista, pobre e desprovida de aura, a qual já não vincula o homem a si, mas sim a diversos aparatos tecnológicos forjados para suprir a miséria que se instalou. O vidro é em geral o inimigo do mistério (Idem, 117). O aparecimento do vidro é simultâneo à reação de um homem cujos "vestígios sobre a terra" estavam sendo abolidos (BENJAMIN, 1985, 118). No vidro nada se fixa, ao contrário da madeira que se deixa marcar. A superfície lisa do vidro parece evocar as relações fugidias, passageiras, onde na convivência humana o outro só será interessante enquanto tiver utilidade. O mesmo acontece com os objetos. Os rastros de cultura humana vão aos poucos sendo substituídos. Fenômenos 
como massificação e uniformização apagam as diferenças, "os vestígios do humano", as diferenças cedem espaço à padronização, nos tornamos então, another brick in the wall. Porém, por que denominar cultura de vidro? Segundo Benjamin, o vidro é inimigo do mistério e da propriedade, representa a pobreza dessa nova forma de cultura. Ela deixa de carregar consigo a aura e a beleza da singularidade, traz somente a generalização fria e cruel, no fenômeno da massificação, única alternativa para o isolamento - selo do individualismo.

\title{
3 A narrativa e causas de seu declínio
}

Não é a toa que a crescente individualização tem sido marca registrada do nosso tempo. O crescimento da tecnologia promoveu diversos avanços em diversas áreas, mas especialmente na maneira como nos comunicamos e interagimos. Se a pobreza de experiências levou à criação de um meio de escape para o cansaço e o desespero do homem extenuado nas atribulações do dia (BENJAMIN, 1985, 118), surge, na figura do camundongo Mickey, a possibilidade de sonho). Ele simboliza o milagre da tecnologia, uma representação de que a mesma pode devolver sentido à vida, dar razão de ser. Essa esperança se configura agora na figura das redes sociais. Diante disso, Benjamin explica que através da tecnologia:

\begin{abstract}
A natureza e a técnica, o primitivismo e o conforto se unificam completamente, e aos olhos das pessoas, fatigadas com as complicações infinitas da vida diária e que veem o objetivo da vida apenas como o mais remoto ponto de fuga (...), surge uma existência que basta a si mesma, em cada episodio, do modo mais simples e mais cômodo, e na qual um automóvel não pesa mais que um chapéu(...) (BENJAMIN, 1985, p. 119).
\end{abstract}

Um dos exemplos do "milagre tecnológico" está no aparecimento do camundongo Mickey, sempre capaz de solucionar as complicações do dia-adia. Com as redes sociais o cenário não é diferente: as mesmas tornam-se saída para que o individuo possa se salvar do fastio do sempre igual (das Immer-gleiche), da vida cansativa e desenvolver para as mesmas um ambiente artificial e individual, no qual o homem, no conforto do seu isolamento, possa criar seu próprio mundo, onde as ideias ali expostas não encontram 
adversários, onde as aparências são a garantia de perfeição e felicidade, enfim, uma nova forma de cultura: a do vidro. Aqui faz-se notar o confronto entre a vida individual e isolada e o apaziguamento de uma existência em constante troca com o outro - que toma a feição de um dos aspectos mais importantes para o surgimento da narrativa: a troca de conhecimentos, principalmente em viagens. A experiência de vivenciar o local visitado e assimilar novos conhecimentos é o estofo da arte de narrar.

A baixa de ações da experiência, além de afetar as relações e a cultura, também afetou a narrativa. $O$ declínio da experiência se dá justamente no que diz respeito às experiências negativas citadas, como o horror da guerra, a experiência do corpo pela fome, a inflação, a crise econômica e a moral dos governantes (BENJAMIN, 1985, 115). O narrador necessita da experiência para produzir a sua narrativa, pois a experiência que passa de pessoa para pessoa é certamente a fonte a que recorreram todos os narradores, e sua extinção produziu o emudecimento dos indivíduos e o enfraquecimento dessa forma de arte, causando transformações radicais no mundo exterior e no mundo ético. A mudança se dá no que diz respeito às novas configurações históricas e econômicas, tanto no plano coletivo como ético-individual, no que diz respeito à recepção do "patrimônio cultural que a experiência não vincula mais a nós. (BENJAMIN, 1985, 115)

\section{Os narradores e seus tipos}

Entre os narradores, apesar da diversidade, há dois tipos fundamentais: o viajante e a do camponês sedentário. $O$ viajante traz o saber de terras distantes, o camponês sedentário o recolhe e passa adiante. O primeiro tipo é retratado por Benjamin na figura de Nicolai Leskov, que nem sempre foi um escritor, mas começou tal oficio depois de realizar diversas viagens a trabalho pelas terras russas, revelando assim, as experiências vivenciadas durante as mesmas. Uma das características mais importantes da narração, e que é encontrada nos contos de Leskov, é seu senso prático. Sua utilidade se dá no que diz respeito à arte de dar conselhos, que infelizmente está se perdendo 
juntamente com a experiência. De acordo com Benjamin, "essa utilidade pode consistir num ensinamento moral, seja numa sugestão prática, num provérbio ou numa norma de vida - de qualquer maneira, o narrador é um homem que sabe dar conselhos..." (BENJAMIN, 1985, 200). O narrador nesse sentido, é dotado de experiência e através da narração passa sabedoria. A arte de narrar está definhando porque a sabedoria - o lado épico da verdade - está em extinção. Porém, esse processo vem de longe" (BENJAMIN, 1985, 201). Mas Benjamin não demoniza o aparecimento da técnica ao ser responsabilizada em parte, pela extinção da arte de narrar. "Nada seria mais tolo do que ver [nesse processo] um "sintoma de decadência, ou uma característica "moderna". [Ele] expulsa gradativamente a narrativa da esfera do discurso vivo e ao mesmo tempo dá uma nova beleza ao que está desaparecendo" (BENJAMIN, 1985, 201), pois a arte de narrar vai perdendo sua aura. É preciso saber que a perda da arte de narrar "tem se desenvolvido concomitantemente com toda uma evolução secular das forças produtivas" (Idem, 201).

\section{0 romance a narrativa: duas faces opostas}

O autor aponta como um dos principais responsáveis pelo definhar da narração, o desenvolvimento do romance. $O$ romance não se origina da experiência, surge do isolamento. Enquanto a arte de narrar era cultivada no seio das comunidades artesanais, o escritor do romance é o individuo isolado que não passa conselhos e nem sabe dá-los, como exemplifica Benjamin apontando Dom Quixote, um dos maiores do gênero: "Dom Quixote, mostra como a grandeza de alma, a coragem e a generosidade de um dos mais nobres heróis da literatura são totalmente refratárias ao conselho e não contêm a menor centelha de sabedoria" (BENJAMIN, 1985, 201).

Quando surgiram tentativas de adicionar estes aspectos que faltam no romance, surgiu o romance de formação, que não se afasta da estrutura original do romance, mas possui insuficiência dos aspectos amplamente encontrados na narrativa. Aquele que escuta uma história está em companhia do narrador, porém o leitor do romance é solitário, pois o mesmo se alimenta de um material 
estéril, que não possui ligação com os aspectos da vida real. O escritor do romance seduz seu leitor com uma ilusão para preencher sua vida vazia e sem sentido. A narrativa vai se tornando arcaica quando o romance encontra sua ascensão junto à burguesia e seu modus vivendi.

A substituição da narrativa pela informação é exemplificada em uma citação de Villemessant, afirmando que "o incêndio num sótão do Quartier Latin é mais importante que uma revolução em Madri”, demonstrando assim que o saber, que outrora vinha de longe, encontra menos ouvintes que os fatos mais próximos. A informação é apontada por Benjamin como outro fator que contribuiu para o declínio da arte de narrar, porque ela já chega explicada. Isso impede a reflexão, impede ao leitor interpretar livremente a história. $O$ autor exemplifica o poder de interpretação da narrativa com o conto de Heródoto acerca da história do rei egípcio Psammenit. O conto carrega um ar de mistério que suscita o questionamento e a livre interpretação. Questiona-se a respeito do porquê de o rei não demonstrar perturbação para com a humilhação de seus entes próximos, mas abalar-se, a ponto de cerrar os punhos, ao avistar, no cortejo dos vencidos, um seus servidores, acorrentado.

A narrativa por si só não pode existir sem que haja quem a ouça e assim retransmitir o que fora dito. $O$ processo de gravação na memória passa por um certo esquecimento de si mesmo, de assimilação do que está sendo proferido. "A memória é a mais épica de todas as faculdades" (BENJAMIN, 1985, 210). Quando o narrador conta com a naturalidade e abre mão de certas sutilezas psicológicas, consegue conquistar o ouvinte, e consequentemente ajudará a preservar a narrativa. Com o aparecimento da técnica chegam ao fim igualmente as atividades "tediosas", que outrora favoreciam a reflexão - estofo da arte de narrar. O dar-se tempo para pensar, tirar conclusões e meditar é uma disposição inerente ao narrador. A comunidade artesanal é seu habitat. Diz Benjamin: "O tédio é o pássaro de sonho que choca os ovos da experiência" (BENJAMIN, 1985, 204). A natureza do trabalho artesanal, sua lentidão e a concentração exigidas sugerem que a arte de narrar já não seria possível no tumulto da metrópole, movida pela aceleração exigida para a vida moderna. "Contar histórias sempre foi a arte de contá-las de novo, e ela se perde quando 
as histórias não são mais conservadas. Ela se perde porque ninguém mais fia ou tece enquanto ouve a história" (BENJAMIN, 1987, 205).

O fim de tais atividades e sua consequência talvez venha a reforçar 0 caráter artesanal da narrativa, pois a mesma é produzida de forma minuciosa, detalhada e leva consigo a marca do seu narrador, ligando-o ao seu trabalho, diferente da técnica industrial, que causa estranheza. O narrador pertence a "um mundo de artífices" (BENJAMIN, 206). A narrativa não está interessada em transmitir sua essência, como um relatório ou informação, mas a mesma mergulha na vida daquele que narra e tece sua história. As histórias que outrora eram contadas sem importar a demora e os detalhes, agora não tem valor, se não forem curtas. Com a fugacidade das relações e do consumo, tudo é feito para ser devorado de imediato, consumido com rapidez, desvirtuando todo o lento processo de camadas superpostas, geração a geração, que faz parte da estrutura da narrativa. Benjamin $(1987,206)$ explana, "Assistimos em nossos dias ao nascimento da short story, que se emancipou da tradição oral e não mais permite essa lenta superposição de camadas finas e translúcidas, que representa a melhor imagem do processo pelo qual a narrativa perfeita vem à luz do dia(...)".

A mudança de visão sobre a morte configura-se como outro fator determinante no declínio da narrativa. A morte perdera sua função social, que consistia no ritual coletivo de passagem do individuo para seu fim. Os grandes nobres e reis que antes eram cercados pelos seus entes agora são escondidos, o luto foi aos poucos sendo substituído pela frieza emocional, pois a convenção não permite mais externar emoções. Emoções essas que no momento de agonia do moribundo provocavam a histeria e o desespero em seus parentes e amigos. A morte outrora era vista como um espetáculo público da vida do indivíduo, seja por estar rodeado de seus entes em seus momentos finais, seja por estar assistido por uma imensa plateia em uma execução publica, sobre este momento, o autor cita a inscrição de um relógio solar de lbiza de um ditado latino, Dubia omnibus, ultima multis, que significa (Esta hora é) incerta para todos e a última para muitos. Com o declínio da arte de narrar, o espaço para a morte, na consciência dos indivíduos, se embota. A burguesia expulsou a morte 
do mundo dos vivos, ao desenvolver instituições onde os moribundos são depositados para seus últimos momentos, na tentativa de abolir a imagem do inevitável de suas próprias vidas. Nesse meio de agonia, desfilam sobre o narrador, imagens, visões de si mesmo, as quais surgem sem que o individuo se dê conta, afloram em seus gestos e olhares. Benjamin considera que é no momento da morte que o saber e a sabedoria do homem, com sua experiência de vida, assumem uma forma transmissível, conferindo ao narrador, autoridade sobre o que está sendo dito. A autoridade deriva da morte por remeter esta à história natural, caminho inevitável de todos os seres.

\section{CONCLUSÃO}

Em Experiência e pobreza, Walter Benjamin inicia o primeiro parágrafo falando da importância da experiência e de sua transmissão aos mais jovens. Devido a diversos fatores e acontecimentos históricos a mesma vem se diluindo e levando junto de si a arte de narrar, a qual desde antigamente carrega em sua estrutura uma sabedoria prática para a existência. Com tamanha miséria, surgiram novas formas para suprir o vazio que se estabelecera, transformando a cultura e exigindo o surgimento de novas ciências com um emaranhado de ideias, nem sempre utilizáveis para a existência.

A antiga forma de cultura, com a qual o homem mantinha uma identidade, desaparece. Ela é exemplificada no conto A Alexandrita (BENJAMIN, 1985, 210) que coloca o leitor nos velhos tempos em que "as pedras nas entranhas da aterra e os planetas, nas esferas e celestes se preocupavam ainda com o destino do homem". Ela foi substituída pela cultura de vidro, que uniformiza e nivela todos, revelando a opacidade das relações humanas, sua fugacidade. Esse fenômeno é cada vez mais presente na contemporaneidade, principalmente nos grandes centros urbanos, onde vivemos uma vida acelerada e marcada por simulações e simulacros. O outro agora é visto com útil ou inútil ao objetivo que se postula. Ao contrário, com a prática da arte de narrar, "o narrador é a figura, na qual o justo se encontra consigo mesmo" (BENJAMIN, 1985, 221)

Simulacros como o camundongo Mickey são ferramentas nas quais a 
felicidade é simulada. Se o Mickey era o fazedor de milagres da época do Benjamin, a variedade de redes sociais são os fazedores de milagres da nossa época. Uma das mais belas críticas a este "esconder de outra face" está na música Shiny Happy People, do R.E.M. Só devemos mostrar alegria, outros sentimentos negativos devem ser escondidos - mandamento típico dos novos paradigmas de comportamento ditados pela tecnologia, afinal de contas, tristeza e outros sentimentos negativos, na verdade tão naturais, passam a serem evitados. São "ruins" para a propaganda. Não é à toa que diante da morte, que tinha um lugar de atenção nas casas e nas praças, as pessoas assumiram outra atitude. Ela agora é expulsa do mundo dos vivos, como algo que não devesse ser sequer imaginado, que dirá visto. O desenvolvimento do romance também acarretou o declínio da narrativa, pois este, ao contrário da experiência, não retira seus elementos da realidade, mas sim de ilusões que seduzem seus solitários leitores, em busca de uma chama para aquecer sua vida fria e vazia.

Com o advento da técnica industrial, a narrativa perdeu outro aliado forte na sua preservação: o tédio, trazido pelas atividades manuais, que faziam o ouvinte perder-se em pensamentos enquanto fazia seu trabalho, gravando em sua memória a sabedoria transmitida. Por ultimo, as diversas experiências negativas que se estabeleceram no início do séc. XX emudeceram as vozes que outrora enriqueciam de conselhos e lições as gerações vindouras. É interessante notar que os idosos, sempre tem alguma história para contar sobre seu tempo. Pergunto-me se os jovens de hoje também serão assim no futuro, já que as experiências, sejam na sua forma de conselho ou na sua forma pura, são deixadas de lado como algo sem importância. É preciso retomar o caminho perdido, para que todos possam também encontrar o verdadeiro ouro em seus vinhedos. Para Benjamin esse tesouro está relacionado à percepção existente nas comunidades artesanais, onde o corpo do homem se fazia presente reivindicando sua inteireza. Nele, tanto o olho, a mão, como a alma deixavamse interagir harmoniosamente, em perfeita conexão e medida.

\section{REFERÊNCIAS}

Mestrando em Filosofia pela Universidade Estadual do Ceará (UECE). Brasileiro, residente em Fortaleza-CE. Email: Andrey.fb.ce@hotmail.com 
BENJAMIN, Walter. Experiência e pobreza. In: Magia e Técnica. Arte e Política. Tradução de Sergio Paulo Rouanet; Prefácio de Jeanne Marie Gagnein. $3^{\mathrm{a}}$ ed. São Paulo: Brasiliense, 1987. p.115-119. (Obras escolhidas,1)

. O Narrador: considerações sobre a obra de Nikolai Leskov.

In: Magia e Técnica. Arte e Política. Tradução de Sergio Paulo Rouanet; Prefácio de Jeanne Marie Gagnein, São Paulo: Brasiliense, 1985. p. 197-221. (Obras escolhidas, 1 )

CALLADO. Tereza de Castro. Walter Benjamin: A Experiência da Origem, Fortaleza: Eduece, 2006.

MOGENDORFF, J. R.. "A Escola de Frankfurt e o seu legado". In: Verso e Reverso; v. 26, n. 63: Ano XXVI, 2012

LIMA, João Gabriel; BAPTISTA, Luis Antonio. Itinerário do conceito de experiência na obra de Walter Benjamin. Revista Princípios. v. 20, n. 33, 2013

MITROVITCH, Caroline. Experiência e Formação em Walter Benjamin. UNESP; Edição: , 2011.

SCHLESENER, Anita Helena. Os Tempos da História. Leituras de Walter Benjamin. Liber Livro; Edição: 1aㅗ, 2011.

SILVA, Joao Gabriel Lima Da. Castelo Da Experiência - Walter Benjamin e a Literatura. Editora: APPRIS, $1^{\circ}$ Edição, 2015. 